\title{
AVALIAÇÃO DAS PERDAS NA DISTRIBUIÇÃO DE ÁGUA: ESTUDO DE CASO EM SÃO BENTO BAIXO, NOVA VENEZA-SC.
}

\author{
ASSESSING LOSSES IN WATER DISTRIBUTION: CASE STUDY IN \\ SÃO BENTO BAIXO, CITY OF NOVA VENEZA, STATE OF SANTA CATARINA \\ Sidnei da Silva Salamoni ${ }^{1}$ \\ Juliano Possamai Della e Álvaro José Back ${ }^{2}$
}

\begin{abstract}
Resumo
Nos sistemas de abastecimento de águas existem perdas inerentes ao sistemas, que representam uma parcela importante nos investimentos em abastecimento de água. Para a melhoria da eficiência do sistema e redução de custos, bem como uso mais racional dos recursos hídricos deve-se avaliar as perdas e adotar medidas para reduzi-las a níveis aceitáveis. Este trabalho teve como objetivo avaliar perdas de água de um sistema de abastecimento localizado no distrito de São Bento Baixo, município de Nova Veneza, no extremo Sul de Santa Catarina. Foram analisados os dados de vazão faturada e a vazão medida no macromedidor durante o período de agosto de 2012 a agosto de 2013 em três setores totalizando 555 ligações. As perdas médias no período estudado foram de $32,12 \%$. Os valores de consumo mensal predominam na faixa de 0 a $10 \mathrm{~m}^{3} \mathrm{e}$ somente 3,97\% dos valores foram acima de $25 \mathrm{~m}^{3} / \mathrm{mês}$. Dos hidrômetros pertencentes ao sistema $15,19 \%$ são da categoria do tipo volumétrico e $84,81 \%$ pertencentes à categoria do tipo velocimétricos. As pressões dinâmicas e estáticas estão contempladas através da NBR 12218/1994.
\end{abstract}

Palavras-chave: Perdas de água, Sistema de abastecimento, Hidrômetros.

\begin{abstract}
In the water supply systems exist losses inherent in the systems, which represent a major portion of investments in water supply. To improve the system efficiency and reduce costs, as well as more rational use of water resources should evaluate losses and adopt procedures to reduce them to acceptable levels. This work aimed to evaluate water loss of a water supply system located in the district of São Bento Baixo, City of Nova Veneza, in the extreme south of Santa Catarina State, Brazil. Data flow and flow measured in macro hydrometer during the period from August 2012 to August 2013 in three sectors totaling 555 consumers were analyzed. Average losses during the study period were $32.12 \%$. The monthly consumption values predominate in the range $0-10$ $\mathrm{m}^{3}$ and only $3.97 \%$ of the values were above $25 \mathrm{~m}^{3} / \mathrm{month}$. Hydrometers belonging to the system are $15.19 \%$ of the volumetric type category and $84.81 \%$ belong to the

\footnotetext{
${ }^{1}$ Acadêmico de Engenharia Civil da Universidade do Extremo Sul Catarinense, Rua Luis Darós Salvador, 199. CEP: 88804575, e-mail: salamonisidnei@gmail.com

${ }^{2}$ Professores Curso de Engenharia Civil da Universidade do Extremo Sul Catarinense (UNESC)
} 
category of velocimetric type. The dynamic and static pressures are contemplated by NBR 12218/1994 .

Keywords: Loss of water; supply system, hydrometers.

\section{INTRODUÇÃO}

A implantação de determinadas atividades tem como meta a qualidade e a garantia de excelência no serviço prestado à comunidade. Em sistemas de abastecimento de água não é diferente, sendo que a qualidade dos materiais e a prestação de serviços junto com as devidas manutenções técnicas realizadas em todo sistema, desde a captação até a água tratada destinada ao consumidor final, garantem trabalhar com um nível de perda de água aceitável.

Os sistemas de abastecimento de água são constituídos de unidades como captação, tratamento, reservação e distribuição. Em todas essas unidades ocorrem perdas de água, sejam elas físicas e/ou não físicas (COSTA e PASQUALETTO, 2013). Por outro lado existe a escassez de recursos hídricos de qualidade e boa parte da população mundial já sofre com a falte de água. De acordo com o Programa Ambiental das Nações Unidas, dois terços do planeta enfrentarão condições de tensão com relação à água em 2025, se os padrões de consumo atual continuar (Sabesp, 2013).

As perdas são inerentes ao sistemas, no entanto, deve-se procurar conhecer sua magnitude e identificar as causas das perdas de forma a reduzi-las a níveis aceitáveis. A redução de perdas será num futuro não muito distante, uma realidade, visto que as concessionárias têm feito se representar nos encontros técnicos realizados no Brasil, assumindo a condição de conhecedor das técnicas e da importância de se implantar um programa de redução para alcançar as vantagens financeiras e ambientais dessa iniciativa, caminho percorrido com êxito por várias empresas públicas.

Segundo Tsutiya (2005), grande parte das perdas são causadas por operação e manutenção deficientes das tubulações, e inadequada gestão comercial das companhias de saneamento. Contudo, isso não quer dizer que é possível contar com "perda zero" no sistema de abastecimento de água.

Carvalho et al. (2010) indicam que o índice de perdas no faturamento dos sistemas de abastecimento de água brasileiros (volume não faturado sobre volume produzido) varia entre aproximadamente $27 \%$ e $60 \%$. As perdas de água podem ser divididas em perdas físicas, ocasionadas por vazamentos desde a captação até a 
distribuição e perdas não físicas, ocasionadas por ligações clandestinas, defeitos em hidrômetros, fraudes, entre outras.

Atualmente a grande maioria das empresas/órgão de abastecimento de água tem problemas com perdas físicas e de faturamentos que comprometem a sua saúde financeira e qualidade na prestação do serviço.

Segundo documento elaborado pela ABES (2013), a redução de perdas físicas e de perdas aparentes envolvem uma série de atividades que precisam ser desenvolvidas de forma integra e que normalmente dificulta a estimativa precisa de todas as ações necessárias à identificação e redução das perdas nos sistemas de abastecimento de água.

A situação atual dos prestadores de serviço não favorece os investimentos em redução de perdas. Parte importante dos operadores do sistema não possuem quadro de profissionais em quantidade suficiente e, mesmo quando o tem, não está suficientemente treinado e capacitado para gerenciar os sistemas de modo a manter baixos e sob controle os índices de perdas. Outro fator que agrava é a precária condição física dos sistemas de abastecimento de água, com redes antigas, escassez de equipamento e instrumentos, e até mesmo de cadastros técnicos e comerciais. Em outras palavras, há prestadores que desconhecem as principais características do sistema que operam (ABES, 2013).

Como as ações para reduzir perdas envolvem diversos departamentos de uma operadora de saneamento (como os setores de compra, obras, manutenção, cobrança, marketing, entre outros), a ausência de uma unidade focada na estruturação e acompanhamento de um programa de redução e eficiência energética dispersa esforços e causa descoordenação.

O problema do elevado nível de perdas preocupa as empresas de saneamento (concessionárias publicas e privadas, autarquias e departamentos) pelo menos a partir do início de 2000, especialmente por causa da escassez hídrica que estas empresas enfrentam e pelos altos valores das perdas, gerando demanda adicional num sistema de abastecimento de água já bastante exigido pelo desenvolvimento urbano das cidades brasileiras (ABES, 2013).

Vive-se um momento de reavaliação dos potenciais naturais, da reeducação para o consumo e de se repensar a relação homem-água. Todos têm o hábito de 
desperdiçar tudo, apesar de saber da necessidade de economia, mas chegou a hora de se dar importância a esse fato.

Em sistemas públicos de abastecimento, do ponto de vista operacional, as perdas de água são consideradas correspondentes aos volumes não contabilizados. Esses englobam tanto as perdas físicas, que representam a parcela não consumida, como as perdas não físicas, que correspondem água consumida e não registrada.

Certas atividades econômicas, como a agricultura e o abastecimento de água, por sua complexidade e características próprias embutem certo grau de perda da produção, por isso é utópica a ideia de obter perda zero nestes setores. Mas o que o Brasil não pode é continuar desperdiçando água tratada e recursos financeiros escassos e seguir convivendo com índices elevados de fugas d'água e perdas de receita por má gestão de suas empresas e serviços de saneamento.

Por isso, melhorar a operação e a gestão da área comercial buscando reduzir os prejuízos por desperdícios é uma meta cada vez mais comum aos sistemas de abastecimento de água brasileiros sejam as operadoras públicas ou privadas, estaduais ou municipais.

O Programa Nacional de Combate ao Desperdício de Água (PNCDA, 2003), do Ministério das Cidades, considera a micromedição (medição do consumo realizado no ponto de abastecimento de um usuário), independente de sua categoria ou faixa de consumo, com a utilização de hidrômetros, que podem também receber a denominação de micromedidores. A micromedição é uma atividade essencial ao controle e redução de perdas aparentes, uma vez que, segundo Leão et al. (2007) inibe o desperdício, fornece dados importantes sobre os volumes fornecidos aos clientes, realiza a cobrança real do volume consumido, disponibiliza dados para avaliação do comportamento e tendência dos usuários ao longo do tempo e contribui para uma maior disponibilidade de água à ser distribuída para a população.

Segundo a NBR 8009/97 (ABNT, 1997), o hidrômetro é um "instrumento destinado a indicar e totalizar, continuamente, o volume de água que o atravessa". Geralmente são usados com o intuito de cobrança. Assim, os hidrômetros são largamente utilizados em micromedição, que pode ser entendida como a medição do volume consumido pelos clientes da companhia de saneamento, independente de sua categoria ou faixa de consumo, definido pelo Programa Nacional de Combate às Perdas 
(PNCDA, 2003), como "a medição permanente do volume de água consumido e que é registrado periodicamente por meio da indicação propiciada pelos hidrômetros".

A medição de água pode ser feita de forma direta, lançando um volume em um reservatório de capacidade conhecida ou indireto, por meio das medições de grandezas influenciadas pela passagem de água (ALVES et al., 2004).

Os hidrômetros são classificados de acordo com as sua características construtivas e principio de funcionamento, capacidade de medição ou classe metrológica, sendo que o conjunto dessas características é o que deve ser considerado para a escolha de um medidor adequado. Hidrômetros podem ser do tipo volumétrico e do tipo taquimétrico ou velocimétrico. Essas características influenciam diretamente a precisão da medição, seu custo e vida útil.

Segundo a NBR NM 212 (ABNT, 1999), o hidrômetro tipo turbina ou de velocidade é um "instrumento instalado num conduto fechado, que consiste de um elemento móvel acionado diretamente pela velocidade do fluxo de água, cujo movimento é transmitido por meios mecânicos ou outros, ao dispositivo indicador". Podem ainda ser do tipo monojato, onde um único jato tangencial incide diretamente sobre o componente móvel e aciona o mecanismo medidor, ou do tipo multijato, onde vários jatos tangenciais acionam o funcionamento do hidrômetro.

Os hidrômetros velocimétricos representam quase a totalidade dos hidrômetros usados no país (SANCHEZ et al, 2000), sendo que os medidores monojato inicialmente foram os mais usados devido às suas dimensões mais compactas, menor custo e menor vazão mínima, embora atualmente os multijados já possuam também essas características e atualmente são os mais utilizados no Brasil.

Este trabalho tem como objetivo a avaliação das perdas no abastecimento de água no distrito de São Bento Baixo, município de Nova Veneza, Santa Catarina.

\section{MATERIAIS E MÉTODOS}

A pesquisa foi desenvolvida, no período de agosto de 2012 a agosto de 2013. O distrito de São Bento Baixo tem cerca de 2800 habitantes, com 555 ligações, uma extensão de 22,244 km de tubulação com diâmetros de 50 a $150 \mathrm{~mm}$. A região tem relevo plano com altitude variando de 36 a $41 \mathrm{~m}$. 
As redes são constituídas por dois tipos de canalizações, assim distribuídas:

a) Rede Principal: Diâmetro Nominal $150 \mathrm{~mm}$ (DN 150), PVC (Policloreto de Vinila), com extensão de 1990m e (DN 100), PVC com extensão de 1589m, tubulações com maior diâmetro que tem por objetivo levar água às tubulações secundárias. Estas tubulações também são conhecidas como canalização mestra ou conduto tronco.

b) Rede Secundária: (DN 75), PVC, com extensão de 64m e (DN 50), PVC com extensão de $11941 \mathrm{~m}$, tubulações de menor diâmetro e tem por objetivo abastecer os pontos de consumo no sistema.

c) Ramais: (DN 20) (com extensão de 6660m), mangueira PEAD (Polietileno de Alta Densidade) tem por objetivo fazer a interligação da rede de abastecimento ao consumidor.

Com relação ao traçado das redes do local de estudo, ficou evidenciado como mista, sendo a combinação de rede malhada e ramificada.

A prestação dos serviços de abastecimento de água é feita pela Companhia Catarinense de Águas e Saneamento (CASAN). O sistema de abastecimento de água do São Bento Baixo consiste de distribuição em marcha, sistema este integrado a ETA (Estação de Tratamento de Água São Defende), que se encontra na altitude de $82 \mathrm{~m}$, e desta forma dispensa a utilização de bombeamento. Foram realizadas pesquisas internas nesse distrito que englobam três setores (549, 550 e 551), utilizando-se como base os conceitos e procedimentos técnicos seguidos pela Companhia Catarinense de Água e Esgoto (CASAN, 2013), sendo esta a organização responsável pelo sistema de abastecimento de água no município.

O estudo realizado contou com a colaboração dos servidores da Companhia Catarinense de Água e Esgoto - CASAN. Sendo observados aspectos gerais e específicos relativos às perdas, através de visitas técnicas, avaliações de relatórios e conhecimento teóricos.

Para a determinação do volume distribuído nos três setores, existe um macromedidor instalado junto à ponte sobre o rio Mãe Luzia, limite Nova Veneza (São Bento Baixo) / Criciúma.

Para determinação do volume de água utilizado em São Bento Baixo foram analisados relatórios das equipes de leitura da Companhia Catarinense de Água e 
Esgoto. Estes relatórios baseiam-se nos volumes registrados no período (08/2012 a 08/2013), pelos hidrômetros instalados nas ligações prediais do distrito de São Bento Baixo. Foram analisadas as frequências dos diversos tipos de medidores usados na área em estudo.

\section{RESULTADOS E DISCUSSÕES}

O volume faturado variou de $5486 \mathrm{~m}^{3}$ no mês de agosto de 2012 até $7703 \mathrm{~m}^{3}$ no mês de dezembro de 2012 (Tabela 1). As perdas variaram de 16,17\% em setembro de 2012 a 43,91\% em agosto de 2012 (Figura1). Essas diferenças podem ser explicadas pela variação no dia da leitura dos hidrômetros e do macromedidor. Em termos médios as perdas foram de $32,12 \%$.

Segundo Speck (2012), os valores médios mensais de perdas $\left(\mathrm{m}^{3}\right)$, em Criciúma-SC foram de 43,15\%, São José-SC, 31,50\% e Chapecó-SC, 52,05\%. Araújo (2010) avaliando perdas em sistema de distribuição de água em Cruz de Rebouças, Município de Igarassu - PE, encontrou valores médios de perda global em 32,26\%. Costa e Pasqualetto (2013), concluiram que em Goiatuba-Go, as perdas totais do sistema representam 32,94\%. Segundo Bais Martins (2008), o percentual médio de perdas, considerando no intervalo de fevereiro a agosto de 2008, no bairro de Buriti, Campo Grande - MS, corresponde a 60,96\%, bem acima da média apresentada na cidade de Campo Grande - MS, que apresenta a média de 50\% de perdas em seu sistema de abastecimento.

Tabela 1 - Volumes medidos e índice de perdas total de água no distrito de São Bento Baixo, Nova Veneza (SC)

\begin{tabular}{llllll}
\hline \multirow{2}{*}{ Mês/ano } & Dias & \multicolumn{3}{c}{ Volume $\left(\mathrm{m}^{3}\right)$} & \begin{tabular}{c} 
Perdas \\
\cline { 3 - 5 }
\end{tabular} \\
\cline { 3 - 5 } & Hidrômetro & Macromedidor & Diferença & 43,91 \\
\hline Ago/12 & 31 & 5486 & 9780 & 4294 & 16,17 \\
Set/12 & 30 & 7222 & 8615 & 1393 & 39,29 \\
Out/12 & 31 & 5634 & 9280 & 3646 & 31,64 \\
Nov/12 & 30 & 6467 & 9460 & 2993 & 23,75 \\
Dez/12 & 31 & 7703 & 10103 & 2400 & 36,87 \\
Jan/13 & 31 & 6598 & 10451 & 3853 & 14,60 \\
Fev/13 & 28 & 7242 & 8480 & 1238 & 39,67 \\
Mar/13 & 31 & 6307 & 10455 & 4148 &
\end{tabular}




\begin{tabular}{llllll} 
Abr/13 & 30 & 6260 & 9660 & 3400 & 35,20 \\
Mai/13 & 31 & 6607 & 9528 & 2921 & 30,66 \\
Jun/13 & 30 & 6568 & 9219 & 2651 & 28,75 \\
Jul/13 & 31 & 6064 & 9667 & 3603 & 37,27 \\
Ago/13 & 31 & 6484 & 9993 & 3509 & 25,10 \\
\hline Total & 396 & 84642 & 124691 & 40049 & 32,12 \\
\hline
\end{tabular}

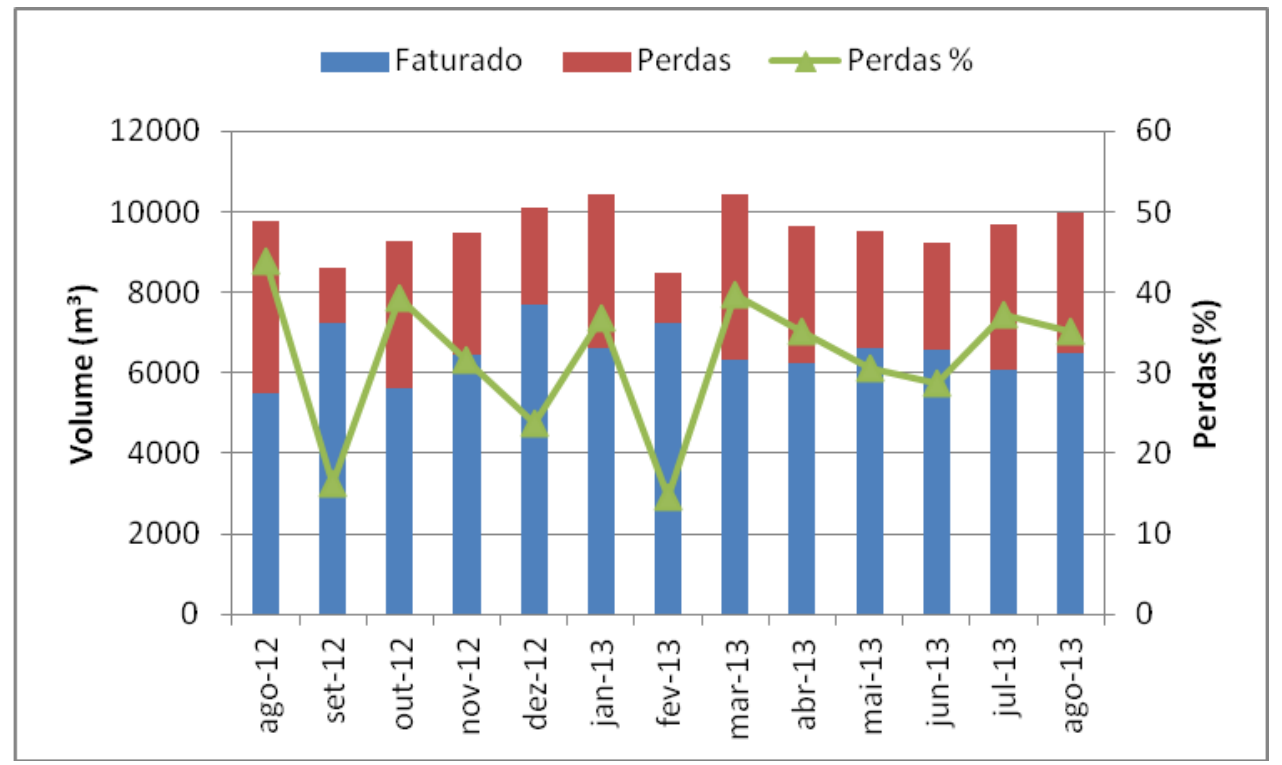

Figura 1 - Demonstrativo de perdas no distrito de São Bento baixo, Nova Veneza (SC)

Um dos motivos de vazamento e consequentemente perdas de água esta voltado no péssimo estado de uma tubulação, por este motivo, deve-se conhecer bem o sistema, para realizar um acompanhamento correto do estado de conservação e a progressão da deterioração do sistema.

O componente que merece mais atenção são os vazamentos na adução, função do estado da tubulação e o material utilizado, sua idade, pressão adequada, execução da obra, elementos de proteção contra golpes e consequentes rompimentos em caso de interrupção do fornecimento de energia. Trata-se de um componente crítico do sistema de abastecimento, merecendo especial atenção no que diz respeito à manutenção sistemática de caráter preventivo. Ressalta-se qual manutenção preventiva, elétrica ou hidráulica, como o conserto das tubulações obstruídas por incrustações ou reparos de vazamento, muitas vezes não é feito ou é adiada para evitar o desgaste político junto à 
população, pois paradas no sistema provocam interrupções no fornecimento de água por muitas horas. Tal procedimento, no entanto, acaba comprometendo o comportamento do sistema, aumentando muitas vezes as perdas de cargas bem como as perdas e o risco de interrupções mais demoradas, por falhas e rompimento.

A manutenção preventiva e a adoção de procedimentos operacionais e treinamento de pessoal para a realização de manobras adequadas é vital para que se evitem rompimentos causados por aumentos súbitos de pressão, que podem ocorrer em cascata, refletindo por meio de múltiplos rompimentos, principalmente nas redes de distribuição.

A falta de instalação ou manutenção de ventosas pode ser um importante fator que propicia a ocorrência de aumento de pressão e consequente rompimento de adutoras, devendo merecer especial atenção. Em sistemas pressurizados por bombeamento, também se deve prestar especial atenção à instalação de elementos aliviadores de pressões, em caso de parada de funcionamento de bomba.

Os vazamentos que ocorrem nas redes de distribuição incluindo os ramais prediais são muitas vezes elevados, mas estão dispersos, fazendo com que as ações corretivas sejam complexas, onerosa e de retorno duvidoso, se não forem realizadas em critérios e controle técnicos rígidos. Nesse sentido é necessário que as operações de controle de vazamentos sejam precedidas por criteriosa análise técnica e econômica.

A redução do vazamento e das perdas é uma parte crítica de qualquer estratégia de eficientização de companhias de água. Embora existam vastas diferenças entre as taxas de água, faturadas das companhias de água nenhuma delas esta imune a grandes perdas de vazamento de água.

A relação entre nível de perdas em uma companhia de saneamento e a sua eficiência operacional e econômica é total, ou seja, quanto menor o índice de perdas, menor o custo na operação do sistema desde a captação ate o consumo final.

$\mathrm{Na}$ Tabela 2 constam as frequências das leituras em faixas de consumo. Observa-se que predomina $(53,69 \%)$ do consumo mensal variando de 0 a $10 \mathrm{~m}^{3}$. Na faixa de 10 a $25 \mathrm{~m}^{3}$ foram observadas $42,34 \%$ das leituras e somente $3,96 \%$ apresentaram valores acima de $25 \mathrm{~m}^{3}$. Uma das leituras por se tratar de um grande consumidor, (Indústria de Confecção), apresentou valores acima de $762 \mathrm{~m}^{3}$. Outro dado que se pode levar em consideração é que $37,29 \%$ dos hidrômetros instalados no distrito 
foram fabricados entre 1984 e 2008, sendo assim com mais de cinco anos de uso. Tomaremos como exemplo o hidrômetro A10C043324 (Tabela 3) em que:

$$
\begin{aligned}
& \text { A = Código/capacidade ( } 3 \mathrm{~m}^{3} / \text { hora); } \\
& 10 \text { = Ano de Fabricação (2010); } \\
& \text { C = Código/Marca (Ningbo); } \\
& 043324 \text { = número de Cadastro. }
\end{aligned}
$$

Tabela 2 - Indicação de percentuais dos hidrômetros utilizados

\begin{tabular}{lll}
\hline Volume de leitura $\left(\mathrm{m}^{3}\right)$ & Média de Consumo $\left(\mathrm{m}^{3}\right)$ & $\%$ \\
\hline 0 a 10 & 298 & 53,69 \\
10 a 25 & 235 & 42,34 \\
25 a 50 & 19 & 3,43 \\
+ de 50 & 2 & 0,36 \\
762 & 1 & 0,18 \\
\hline Total & 555 & 100,00 \\
\hline
\end{tabular}

A pressão excessiva é outro fator de grande relevância e que pode causar rompimento do tubo, aumentando as perdas de água. Foram coletadas em campo as medidas de pressão em três pontos distintos, uma na entrada do local próximo ao macromedidor, outra aproximadamente a $2000 \mathrm{~m}$ e outra no final da rede de distribuição, havendo uma variação de três m.c.a. na pressão dinâmica e cinco m.c.a. na pressão estática (Tabela 3). A coleta dos dados de pressão na rede foi realizada nos cavaletes residenciais, diferença topográfica existente entre o terreno e o cavalete foi considerada na simulação hidráulica.

Segundo a norma técnica NBR 12218/1994 (ABNT, 1994), a pressão estática máxima das tubulações distribuidoras deve ser de $500 \mathrm{KPa}(50 \mathrm{mca})$, e a pressão dinâmica mínima, de $100 \mathrm{KPa}$ (10 mca). Valores fora desta faixa podem ser aceitos desde que justificados técnica e economicamente (YOSHIMOTO et al., 1999). Portanto, as redes distribuidoras devem trabalhar com pressão mais reduzida possível, contanto que seja suficiente para atender às condições de pressão mínima definida pela norma.

Tabela 3 - Pressões estática e dinâmica 


\begin{tabular}{llllll}
\hline & & \multicolumn{2}{c}{ Vazão } & \multicolumn{2}{c}{ Pressão (mca) } \\
\hline Hidrômetro & Hora & Data & $\left(\mathrm{m}^{3} / \mathrm{h}\right)$ & Dinâmica & Estática \\
\hline Y05S002237 & 17h07min & $05 / 10 / 2013$ & 1044 & 21 & 37 \\
A10C043324 & $17 \mathrm{~h} 18 \mathrm{~min}$ & $05 / 10 / 2013$ & 306 & 21 & 37 \\
A05S504810 & 17h32min & $05 / 10 / 2013$ & 677 & 24 & 42 \\
\hline
\end{tabular}

No levantamento efetuado com os hidrômetros (Tabela 4) constatasse que $15,32 \%$ do hidrômetros são do tipo volumétrico com capacidade de $3 \mathrm{~m} 3 / \mathrm{h}, 14,23 \%$ do tipo multijado com capacidade $3 \mathrm{~m} 3 / \mathrm{h}, 11,53 \%$ multijado com capacidade $5 \mathrm{~m}^{3} / \mathrm{h}, 0,18 \%$ do tipo multijado com capacidade $7 \mathrm{~m} / \mathrm{h}, 0,18 \%$ do tipo multijado com capacidade $20 \mathrm{~m}^{3} / \mathrm{h}$ e $58,56 \%$ do tipo unijato com capacidade $1,5 \mathrm{~m}^{3} / \mathrm{h}$.

A principal diferença entre hidrômetros monojatos e multijatos é o número de jatos que incidem na turbina do hidrômetro, dessa forma os hidrômetros monojatos possuem um tamanho menor que os hidrômetros multijatos com a mesma vazão.

Segundo Carvalho (2010), os hidrômetros multijatos se caracterizam pela incidência de vários jatos na turbina. A câmara de medição onde se localiza a turbina possui furos distribuídos radialmente na parte inferior e na parte superior, de modo que a água entra na câmara de medição pela parte inferior e é expulsa pela parte superior. A entrada de água através de vários orifícios na câmara de medição permite um funcionamento mais balanceado da turbina em seu eixo de rotação, resultando em uma maior vida útil do equipamento.

Tabela 4 - Tipo de hidrômetros usados.

\begin{tabular}{ccccc}
\hline Hidrômetros & Quantidade & $\%$ & Tipo & Capacidade $\left(\mathrm{m}^{3} / \mathrm{h}\right)$ \\
\hline AxxC & 84 & 15,19 & Volumétrico & 3 \\
AxxL & 2 & 0,36 & Multijato & 3 \\
AxxN & 2 & 0,36 & Multijato & 3 \\
AxxT & 7 & 1,27 & Multijato & 3 \\
AxxS & 67 & 12,12 & Multijato & 3 \\
AxxX & 1 & 0,18 & Multijato & 3 \\
BxxC & 64 & 11,57 & Multijato & 5 \\
YxxC & 224 & 40,51 & Unijato & 1,5
\end{tabular}




$\begin{array}{ccccc}\text { YxxS } & 55 & 9,95 & \text { Unijato } & 1,5 \\ \text { YxxX } & 44 & 7,96 & \text { Unijato } & 1,5 \\ \text { CxxT } & 2 & 0,36 & \text { Multijato } & 7 \\ \text { ExxC } & 1 & 0,18 & \text { Multijato } & 20\end{array}$

Normalmente os hidrômetros monojatos são mais baratos que os respectivos hidrômetros do tipo multijato. Atualmente no Brasil são fabricados hidrômetros monojatos com vazão nominal de $1,5 \mathrm{~m}^{3} / \mathrm{h}$ e 3,0 m³/h, já os hidrômetros multijatos são encontrados também com vazões superiores.

A recomendação para o problema de perdas no distrito de São Bento Baixo, é que seja realizada uma melhora nas gestões comercial e operacional do setor, além de um maior número de pesquisas a campo (já que no período analisado foi efetuada apenas uma vez com a equipe de geofonamento, e uma vez com as equipes de fraudes), pois com uma melhora na gestão comercial, traria mais eficiência no controle de fraudes, o que significa faturar mais pela água que é produzida, otimizando seu uso e evitando seu desperdício. E, na parte de gestão operacional, a melhora seria com relação às perdas físicas no sistema, pois com uma equipe eficiente e bem equipada, diminuiria o tempo de ocorrência dos vazamentos, melhorando a eficiência do combate as perdas.

Outra recomendação seria um trabalho de conscientização com a população a respeito das fraudes e ligações clandestinas, alertando para os riscos causados, caso essas fraudes sejam detectadas pela empresa, e também do prejuízo causado por esses infratores para os clientes da companhia, que sofrem com o aumento da tarifa devido ao índice de perdas existentes.

Portanto, com um investimento na área de combate as perdas de água no sistema de abastecimento, as vantagens obtidas serão no ponto de vista empresarial, que terá lucros financeiros com essas medidas, no ponto de vista do consumidor, que poderá ter suas tarifas reduzidas e terá uma melhor eficiência nos problemas de falta de água, e no ponto de vista ambiental, pois evitando o desperdício, a água estará disponível para a população por um tempo maior.

\section{CONCLUSÕES}

Com base nas observações do estudo de caso pode-se concluir que: 
1. O percentual médio de perdas atuais, considerando o intervalo de agosto de 2012 a agosto de 2013, corresponde a 32,12\%. Para determinação desse valor, levou-se em consideração o volume disponibilizado e micromedido. Este é um valor considerado baixo pela literatura especializada. Considerado abaixo também da média apresentada na Agência de Criciúma, que apresenta a média de 43,15\% de perdas de água em seu sistema de abastecimento.

2. O consumo mensal da maioria das unidades estudadas é de até $10 \mathrm{~m}^{3}$. Somente 3,96\% dos hidrômetros apresentaram valores acima de $25 \mathrm{~m}^{3}$ mensal, levando em consideração o único grande consumidor, a industria de confecção, que apresentou valores acima de $762 \mathrm{~m}^{3}$.

3. A pressão manométrica no local apresenta valores dentro da faixa exigida pela NBR $12218 / 1994$.

\section{REFERÊNCIAS}

ABNT. ASSOCIAÇÃO BRASILEIRA DE NORMAS TÉCNICAS. NBR-12218: Projeto De Rede de Distribuição de Água Para Abastecimento Publico. Rio de Janeiro, 1994.

ABNT. ASSOCIAÇÃO BRASILEIRA DE NORMAS TÉCNICAS. NBR-8009: Hidrômetro Taquimetrico para Água fria até $15,0 \mathrm{~m}^{3} / \mathrm{h}$ de vazão nominal. Rio de Janeiro, 1997.

ABNT. ASSOCIAÇÃO BRASILEIRA DE NORMAS TÉCNICAS. NBR NM 212: Medidores Velocimétricos de Água Fria até $15,0 \mathrm{~m}^{3} / \mathrm{h}$. Rio de Janeiro, 1999.

ALVES, W. C.; PEIXOTO, J. B.; SANCHEZ, J. G.; LEITE, S. R.(2004) Micromedição. Brasília: Programa Nacional de Combate ao Desperdício de Água, 2004. 171 p. Documento Técnico de Apoio - DTA - A3.

ABES. Perdas em Sistemas de Abastecimento de Agua: Diagnostico Potencial de Ganhos com Sua Redução e Propostas de Medidas para Efetivo Combate. Setembro/2013.

ARAÚJO. F. A. S. Avaliação de Perdas em Setor de Abastecimento de Água em Cruz de Rebouças, Município de Igarassu, Estado de Pernambuco. Recife, 2001. $125 \mathrm{f}$. Dissertação (Mestrado em Engenharia Civil) - Universidade Federal de Pernambuco. 2001.

BAIS MARTINS. T.G. Avaliação das perdas no Sistema de Abastecimento de ÁguaBairro Buriti, Campo Grande/MS. UCDB. 2008.

CARVAlHO, F. S; PEPLAU, G. R; CARVALHO, G. S; PEDROSA, V. A. Panorama de perdas em sistemas de abastecimento de água. In: SIMPOSIO DE RECURSOS HIDRICOS DO NORDESTE, 7, 2004, São Luis. Anais... São Luis: ABRH, 2004. 
CARVALHO, W.F. Medição individualizada de água em apartamentos. Monografia (Especialização em Construção Civil) - Universidade Federal de Minas Gerais, Belo Horizonte, 2010.

CASAN. Companhia Catarinense de Água e Saneamento - Sistema Comercial Integrado - SCI -. Santa Catarina, 2013.

COSTA. C. C. R.; PASQUAletTO, A. Estimativa dos tipos de Perdas de Água Pelo Método Balanço Hídrico no Sistema de Abastecimento de Goiatuba, Goiás. In: CONGRESSO BRASILEIRO DE ENGENHARIA SANITÁRIA E AMBIENTAL, 27. 2013, Goiânia. Anais. Goiânia: ABES, 2013.

LEÃO. N.F. PAIVA. E.B., RIBEIRO. A. J. Z e MATOS. L. C. A Importância da Implantação de Um Projeto de Micromedição Para o Desenvolvimento de Uma Política de Gestão, Controle e Redução de Perdas. Anais do $24^{\circ}$ Congresso da Associação Brasileira de Engenharia Sanitária, Belo Horizonte, Minas Gerais, Brasil, 2007.

PROGRAMA NACIONAL DE COMBATE AO DESPERDÍCIO DE ÁGUA PNCDA. Documento Técnico de Apoio - DTA A2. Ministério das Cidades. Secretaria Nacional de Saneamento Ambiental. Indicadores de Perdas nos Sistemas de Abastecimento de Água. Brasília - DF, 2003. 80p.

SABESP. Companhia de Saneamento básico do Estado de São Paulo. Manual de gerenciamento para controladores de consumo de água. Consórcio Cobrape-Etep, Consórcio Revita, São Paulo, 95p. Disponível em: http://www.sabesp.com.br/uploads/file/asabesp_doctos/Manualdocontrolador.pdf Acesso: 25. out.2013.

SANCHEZ, J. G.; MOTTA, S. A.; ALVES, W. C. Estimativa de volume de água não medido em ligações residenciais por perda de exatidão nos hidrômetros, na cidade de Juazeiro - BA. In: CONGRESSO INTERAMERICANO DE ENGENHARIA SANITÁRIA E AMBIENTAL, 27, 2000, Porto Alegre. Anais... Porto Alegre: ABES 2000.

SPECK, J.A. Perdas de Água: A Situação na Casan e as Ações de Redução no Sul do Estado de Santa Catarina. $4^{\circ}$ Encontro de Técnico, Florianópolis, SC, 2012.

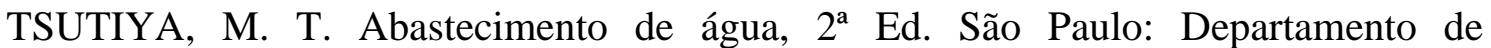
Engenharia Hidráulica e Sanitária da Escola Politécnica da Universidade de São Paulo, 2005.

YOSHIMOTO, P. M., FILHO, J. T., SAREDAS, G. L. Controle da Pressão na Rede. Documento técnico de Apoio D1 - Programa Nacional de Combate ao Desperdício de Água, Brasília, 1999. Disponível em: http://www2.cidades.go.br/pncda. 